\title{
LA GESTIÓN DE LO "INAPROPIADO": DISPUTAS DE SENTIDOS Y PRÁCTICAS EN TORNO A LA AUTONOMÍA Y LA MATERNIDAD EN UNA PROPUESTA DE INCLUSIÓN SOCIAL PARA JÓVENES.
}

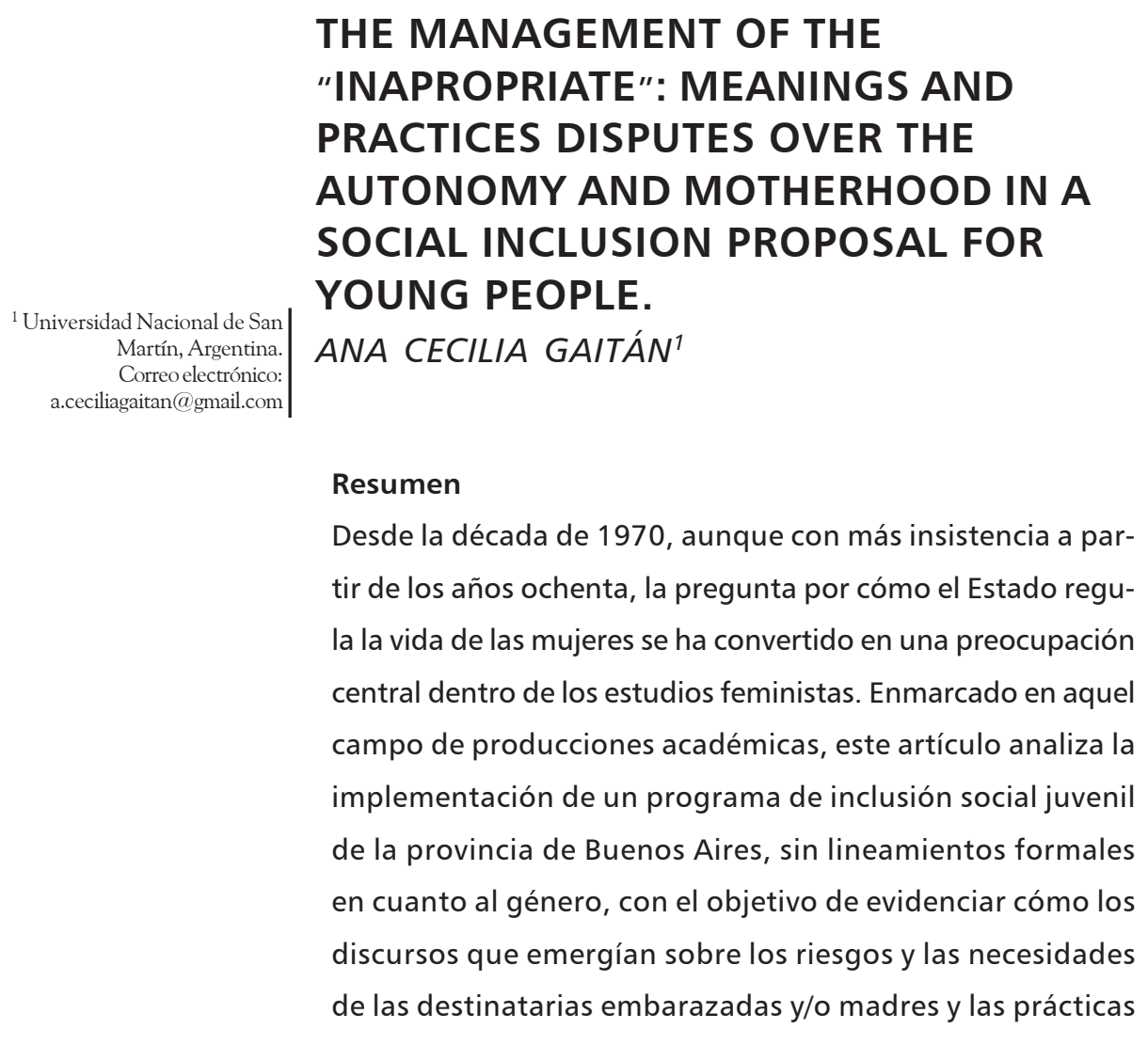


institucionales en las que se inscribían, operaban como formas de gestión estatal del género y la maternidad juvenil. Además de aportar al conocimiento de aspectos aún no lo suficientemente explorados acerca de cómo las relaciones de género son activamente producidas en el marco de las políticas sociales en general, y de las destinadas a jóvenes en particular, el propósito de este artículo es abonar al conocimiento respecto de la complejidad que la regulación estatal del género puede revestir, evidenciando cómo, incluso un mismo Estado local, puede gestionarlo — articuladamente con la edad y la clase social- de manera diferencial y ambigua. Los datos fueron producidos durante un trabajo de campo etnográfico realizado entre el 2012 y 2016, en una implementación local del programa Envión.

Palabras claves: regulación estatal, género, maternidad juvenil, etnografía, estudios feministas

\section{Abstract}

Since the 1970s, but more strongly since the 1980s, the question of how the State regulates women's lives has become a central concern in feminist studies. Framed in that field of academic productions, this manuscript analyzes the implementation of a youth social inclusion program in the State of Buenos Aires, without formal guidelines of gender, with the aim of proving how the discourses that emerged about the risks 
and needs of clients that were pregnant or were mothers and the institutional practices in which they enrolled, worked as forms of State management of gender and youth motherhood. Besides contributing to the knowledge of aspects not yet sufficiently explored about how gender relations are actively produced in the settings of social policies in general, and those aimed at young people, in particular, the article object is to contribute to the knowledge about the complexity of State gender regulations, showing how, even the same local State, can manage it - articulately with age and social classin a differential and ambiguous way. The data were produced during an ethnographic fieldwork carried out between 2012 and 2016, in a local implementation of social program Envión.

Keywords: state regulation; gender; juvenile motherhood; ethnography; feminist studies

RECEPCIÓN: 27 DE JULIO dE 2018/ACEPTACIÓN: 23 DE NOVIEMBRE DE 2018

\section{INTRODUCCIÓN}

Desde la década de 1970, pero más fuertemente a partir de los años ochenta, la pregunta cómo el Estado regula la vida de las mujeres y sus comportamientos maternales se convirtió en una preocupación central dentro de los estudios feministas (Haney, 1996). Principalmente centrados 
en el análisis de las dinámicas de interpretación y redistribución de beneficios estatales; la asignación de ciudadanía política y derechos legales y en la formulación de prácticas penales y disciplinarias, dichas producciones fueron desplazándose desde afirmaciones en torno a la existencia de un único y uniforme régimen de género, hacia el reconocimiento de las múltiples y contradictoras formas en que los Estados modelan las relaciones de género (Haney, 1996; 2000).

A nivel local se han incrementado las investigaciones que, recuperando aquellos aportes, han explorado cómo en las prácticas micro del Estado, se despliegan distintas construcciones simbólicas y culturales respecto al género, la edad y las formas legítimas de inclusión social (Medan, 2013). En sintonía con estas investigaciones y recuperando la propuesta de Haney (2010) de pensar al Estado y sus políticas como instancias de regulación, es decir, como intentos deliberados de guiar y modelar la conducta social de cierta manera en relación a determinados objetivos, este artículo explora cómo, en la implementación del programa de inclusión social juvenil Envión, sin lineamientos formales en cuanto al género, se desplegaban micro operaciones tendientes a forjar arreglos de la "intimidad", normativos del género y la maternidad. A partir del análisis de una de sus implementaciones locales, el objetivo es evidenciar cómo, los discursos que emergían sobre los riesgos y las necesidades de las destinatarias madres (Fraser, 1989) y las prácticas 
institucionales en las que se inscribían, operaban como formas de gestión estatal del género y la maternidad juvenil.

En la Argentina, desde finales del siglo xIx, las mujeres, principalmente vinculadas a la maternidad, se han transformado en objeto de protección e intervención estatal mediante la creación y modificación de la legislación y la implementación de diversos programas y políticas públicas (Nari, 2004; Felitti, 2011). Apelando a distintos recursos, aquellas propuestas estatales han caracterizado, sancionado y construido atributos en cuanto al género y la maternidad, procurando regular sus comportamientos, emociones y deseos. Atendiendo a esto, este artículo pretende mirar la preocupación estatal por las maternidades juveniles, consideradas como "inapropiadas» desde mediados del siglo $x x$, a la luz de las nuevas políticas sociales que reconstruyen el modo de gobierno de lo social y el papel de los/ as individuos (Lister, 2002). Así, al acercar la perspectiva de género a un campo poco indagado en esa clave, el de las políticas de inclusión social para jóvenes, esta investigación abona a la reflexión acerca de cómo "se juegan» las relaciones de género allí donde el Estado se pretende "neutro" (Anzorena, 2013). El trabajo se organiza en cuatro partes. Una inicial donde se describen las principales características del programa de la provincia de Buenos Aires, Envión, y algunos aspectos generales de la implementación local estudiada que, de ahora en más, denominaré La Estrella. ${ }^{2}$ sujetos/as que han colaborado con esta investigación y el anonimato del barrio y del municipio, todos los nombres utilizados son ficticios. Sólo fue conservado el 


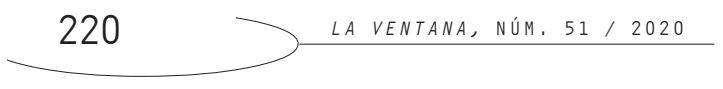

Luego, se delinea la propuesta de participación que aquella implementación local desplegaba para las destinatarias embarazadas y/o madres. En un tercer apartado, se profundizan aspectos sobre dicha propuesta, especialmente, el lugar que ocupaba la articulación con el Espacio de Educación Maternal Comunitaria (EEMC), una iniciativa del gobierno local para atender al "desarrollo normal» de los/as niños/as en el municipio estudiado. Hacia el final, se ofrecen algunas reflexiones respecto a cómo esta propuesta de participación constituía un complejo proceso de intervención institucional donde dos formas de regular el género, la edad y la maternidad eran desplegadas de manera articulada. Los datos fueron producidos en el marco de una investigación cualitativa que privilegió la perspectiva etnográfica (Hammersley y Atkinson, 1994). El trabajo de campo fue realizado entre 2012 y 2016 en la implementación del Envión en un municipio del conurbano bonaerense reconocido por su plataforma de políticas públicas orientadas por

${ }^{3}$ Realicé observación participante en espacios de interacción cotidiana de los programas, con el objetivo

de registrar las prácticas, acciones y discursos de trabajadores/as y destinatarios/as. Llevé a cabo entrevistas semiestructuradas y en profundidad a funcionarias, trabajadores/as y destinatarios/as de los programas. Analicé fuentes secundarias -normativas; notas periodísticas y registros institucionales, entre un discurso de género, de derechos y de inclusión social. ${ }^{3}$ Por último, cabe aclarar que el artículo se focalizará en las propuestas programáticas y en las representaciones y prácticas de los/as agentes estatales y no así, en las participaciones y las contestaciones de las destinatarias madres y/o embarazadas a dichas propuestas. 


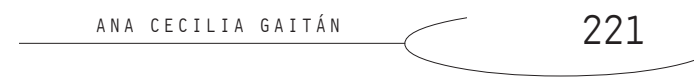

\section{"OTRA PROPUESTA ESTATAL" PARA JÓVENES DE SECTORES POPULARES}

Dirigido a personas de entre 12 y 21 años «en situación de vulnerabilidad social» y/o "padeciendo nece-

sidades básicas insatisfechas», ${ }^{4}$ el Envión formaba parte de un conjunto de programas sociales inaugurados durante los 2000 conforme a la preocupación política por los impactos de la pobre-

${ }^{4}$ El programa definía como "vulnerables" a aquellos que "(...) pertenecen a hogares con inserción laboral precaria, los que no estudian ni trabajan, viven en situaciones familiares de violencia y abandono, residen en viviendas precarias, en barrios con infraestructura y equipamiento inadecuado". Recuperado el 10 de septiembre de 2013 http:// www.desarrollosocial.gba.gov.ar/subsec/ politicas_sociales/programas/envion.php za y la exclusión educativa y laboral juvenil (Llobet, 2013). Su objetivo era brindarles herramientas a los/as jóvenes para que lograsen elaborar un "proyecto de vida" individual - siendo la incorporación al mercado de trabajo formal, su máxima expresión-. Conforme a ello, el programa desplegaba acciones de inclusión, protección y prevención bajo la modalidad de acompañamientos individuales y grupales a procesos de reinserción educativa, laboral y comunitaria; espacios de formación y recreación; asistencia legal y una transferencia condicionada de ingresos ( $\mathrm{TCl}$ ) denominada beca. ${ }^{5}$ A cambio, los/as jóvenes debían cumplir con las normas directamente por cada joven. de participación expresadas en el "acuerdo compromiso» firmado al momento de incorporarse formalmente al programa.

En el municipio considerado, el Envión se implementaba desde el año 2009 y su ejecución estaba bajo la órbita de la dirección local destinada exclusivamente a asuntos de niñez 
y juventud. En la sede del barrio de sectores populares La Estrella, el equipo de trabajadores/as que lo implementaban se encontraba compuesto por una coordinadora, tres jóvenes profesionales provenientes de carreras sociales y tres operadores/as barriales que eran referentes dentro de la comunidad. Además de sus conocimientos técnico y territorial, respectivamente, aquellos/as habían sido convocados/as por dicha dirección debido a sus experiencias de militancia en barrios populares, movimientos sociales, partidos políticos, espacios religiosos y/o pedagógicos relacionados con la niñez y la juventud.

En esta implementación se les otorgaba centralidad a los espacios grupales de discusión y formación. Además de ofertar talleres temáticos diversos — jóvenes y memoria; comunicación; circo; belleza; etc. - cada semana tenían lugar las «asambleas». Descrita por los/as trabajadores/as como «otro espacio de comunicación», como algo alternativo a lo que se les presentaba cotidianamente a los/as jóvenes en sus casas y en otras instituciones estatales más retardatarias y ligadas al control

${ }^{6}$ Además de autopercibirse como garantes de los $\mathrm{DDHH}, \mathrm{los} /$ as trabajadores/as consideraban al programa y a sí mismos/as como una alternativa a las propuestas estatales de "mano dura" destinadas a acabar con la participación juvenil en el delito y con las cuales coexistían (Medan, 2013). Así, se encontraban interesados/as en diferenciarse no sólo

de actores estatales represivos -policía y/o poder judicial-, sino también de otras instituciones tradicionales, como por ejemplo, la escuela. social. La "asamblea» era introducida como el lugar donde aquellos/as podían hablar sin temor a no ser escuchados/ as de manera respetuosa y afectiva, ${ }^{6}$ pero también donde debían «aprovechar» para que «algo más» emergiera (Llobet, 2013). 
No satisfechos/as con solo lograr que los/as destinatarios/ as elaborasen un "proyecto de vida» individual, los/as trabajadores/as del programa en La Estrella se encontraban interesados/as en que aquellos/as reflexionaran en las "asambleas» acerca de cómo sus problemas cotidianos eran parte de una injusticia social, que la delimitaran concretamente e hicieran algo al respecto, tanto en términos individuales como comunitarios (Llobet, 2013).

A pesar de que la apuesta fuerte del Envión en La Estrella eran los espacios colectivos, también tenían relevancia los «acompañamientos cuerpo a cuerpo» y la construcción de los/ as trabajadores/as como referentes positivos. En cuanto a los "acompañamientos», además de físicos, debían ser afectivos y erigirse sobre una lectura minuciosa de la historia y el contexto de cada joven. Por su parte, la construcción de los/as trabajadores/as como referentes, se vinculaba con que estos/ as emitieran mensajes positivos sobre sus propias vidas. Dichas referencias a sus experiencias personales se realizaban con la expectativa de que los/as jóvenes lograsen identificarse con algún aspecto de los "proyectos de vida» de los/as trabajadores/as.

"QUE NO QUEDEN TOMADAS COMO

MADRES"

En el diseño formal del Envión no existía alusión a las relaciones sociales e identidades de género. Aun 
así, la exploración etnográfica de su implementación en La Estrella evidenció que, en su resignificación local, se desplegaban construcciones simbólicas y culturales en torno al género. En efecto, una definición generizada sobre las necesidades y los riesgos que se les presentaban a los/as destinatarios/as (Fraser, 1989; Haney, 1996), operaba como la base sobre la cual se erigían propuestas concretas de participación específicas para mujeres y varones que, de acuerdo a la mirada institucional, debían adoptar para alcanzar la inclusión social. Al igual que lo relevado en programas similares (Medan, 2013), vivir en la inmediatez - «en un presente muy presente» - y no tener un "proyecto de vida» era, para estos/as agentes estatales, un riesgo que amenazaba la inclusión social de los/as jóvenes del barrio.

En sintonía con otros programas de inclusión juvenil, cuando se trataba de mujeres, el Envión de La Estrella conectaba lo «riesgoso» a sus sexualidades (Llobet, 2009), pero no lo hacía de un modo tradicional, es decir, no consideraba las «transgresiones» de las mujeres a las normas sexuales o a la domesticidad como aspectos conflictivos. Por el contrario, era una presunta falta de auto conocimiento y de "autonomía» sobre sus cuerpos lo que las amenazaba, lo que las volvía vulnerables. Que estas destinatarias tuvieran un conocimiento «insuficiente» de sus corporalidades constituía un riesgo en sí mismo, en tanto que no les permitía experimentar - como supuestamente sí lo hacían las jóvenes de otros barrios- de manera 
placentera y segura sus cuerpos. Mantenerse desinformadas sobre sus territorios corporales y sus derechos era algo que, según aquellos/as trabajadores/as, las llevaba no sólo a experimentar relaciones de pareja heterosexuales violentas, sino también, a naturalizarlas. Al hacerlo, las destinatarias se transformaban en "objetos a ser consumidos por otros», perdiendo su condición de sujetas capaces de construir «proyectos de vida» por fuera de los guiones que el barrio, las familias y las parejas escribían para ellas. En este sentido, parte de la propuesta de participación que se reservaba para ellas, giraba en torno a que éstas se adentraran en un proceso de toma de conciencia de la desigualdad de género que las atravesaba. Esto les permitiría, en un escenario de múltiples constreñimientos, iniciar cambios individuales y apreciar los límites de la maternidad como «proyecto de vida» (Gaitán, 2019).

Una vez desnaturalizadas sus situaciones personales y enmarcadas en problemáticas sociales, se esperaba que modificasen relacionamientos considerados opresivos y gestasen un «proyecto de vida» — por fuera de la maternidad-que las ayudara a encontrar la salida del «laberinto de riesgos» que transitaban. Pero, ¿cómo se esperaba que participasen las destinatarias madres y/o embarazadas? ¿Cuál era la propuesta de participación diseñada para ellas?

A pesar de no existir una postura institucional que conceptualizara a la maternidad juvenil como un problema en sí mismo, sí lo era la forma en que muchas de las jóvenes 
se vinculaban con sus hijos/as, y el modo en que ese relacionamiento "afectaba» su participación en el programa y en el armado de un "proyecto de vida» propio. Bajo la premisa de que todos/as los/as jóvenes, de poder hacerlo, querrían participar del Envión, como una oportunidad que se les brindaba y que debían aprovechar, los/as trabajadores/as explicaban sus ausencias y desempeños «deficitarios» en los espacios colectivos, apelando al vínculo de «dependencia excesiva» que forjaban con sus hijos/as.

Comentarios como "con los bebés rajan antes» o "vienen, pero vienen fuera del horario de las asambleas», eran expresiones que aquellos/as, contrariados/as, elaboraban para explicar los tránsitos de dichas jóvenes por el programa. Si bien los/as agentes no desconocían que muchas de ellas eran también constructoras de esas "dependencias», de todos modos, caracterizaban los vínculos como "apropiaciones» desventajosas, a contramano del forjamiento de grados de «autonomía». Así, su intervención se encontraba dirigida a aportar a la modificación de aquellos relacionamientos, a dotarlos de mayor independencia.

Como solían señalarme: "que no dejen su vida por el bebé», "que no queden tomadas como madres». En este sentido, para que las jóvenes re-aprendiesen sus lugares sociales, «a que sus mundos no empezasen y terminasen en sus hijos/as», y que comprendiesen la importancia de construir un «proyecto de vida» propio, las trabajadoras mujeres emitían mensajes 
sobre sus propias vidas. Lo hacían con la expectativa de que pudieran identificarse y empezar a problematizar los mandatos que recaían sobre ellas - entre ellos-, el maternal. Tener entre 20 y 35 años, sin hijos/as, pero con proyectos laborales y parejas heterosexuales "respetuosas», eran algunos de los mensajes que las trabajadoras colocaban sobre sus vidas:

Te interpelan [destinatarios/as], como: «¿Pero qué, Rodrigo [su pareja] te deja sa...?», "A mí no me deja salir nadie, yo soy libre, puedo salir y que eso no implica que le meta los cuernos o que no lo respete, hago mis cosas, él tiene su proyecto individual, yo también y tenemos un proyecto en pareja» [...] Son intercambios que están buenos, o sea, como, de distintas cosas vividas que también se aprenden más allá del taller que se esté dando. (Entrevista a profesional, 26 de marzo de 2013)

Generalmente este tipo de conversaciones se producían en momentos de interacción y sociabilidad que rebasaban en tiempo y espacio a las actividades formales del programa. Durante estos encuentros también se las orientaba en la gestión de recursos estatales y beneficios sociales que les correspondían en su calidad de madres. A la vez, se les brindaba asesoramiento respecto de cómo reestructurar los vínculos con instituciones como la escuela y con los padres de sus hijos/as. 


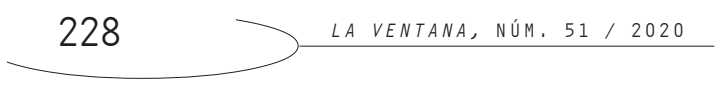

A pesar de que las agentes solían criticar los desempeños paternales de las parejas - algunos destinatarios del programa- dedicaban tiempo a aconsejar a las jóvenes para que atenuasen el nivel de confrontación con institucional orientada a interrogarlos como padres.

ellos. ${ }^{7}$ Aun reconociendo las reiteradas ausencias de estos varones y/o las fluctuaciones al momento de propinar buenos tratos a ellas y a sus hijos/as, muchas de las trabajadoras insistían en que existía una reticencia «nociva», por parte de algunas destinatarias, a dejarlos participar de la crianza y solían sugerirles que arreglasen la situación con los padres de sus hijos/as. De acuerdo a su mirada, esto podía habilitar una distribución de las tareas de cuidado maìs equitativa, lo cual facilitarìa - otorgando maìs tiempo y disponibilidad - el proceso de construcción de un «proyecto de vida» propio.

Cabe destacar que las profesionales de La Estrella no desconocían que la clase social modelaba diferencialmente sus experiencias como mujeres respecto de la de las destinatarias. Cuando emitían sus consejos hacían grandes esfuerzos por mantenerse atentas y críticas respecto de cómo algunas de sus "expectativas de clase media», se colaban. De todos modos, la pretensión de hacerlo, no significaba que necesariamente lo lograran. En efecto, sus interpretaciones parecían no hacer suficiente lugar a la diversidad de intereses que podían tener las diferentes mujeres, ni barajar la posibilidad de que las destinatarias utilizasen la «dependencia» con sus hi- 


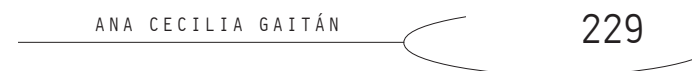

jos/as como una contestación estratégica al tipo de participación esperada, e incluso que constituyese, para ellas, un sitio de poder en un escenario de múltiples constreñimientos. En las interpretaciones que éstas trabajadoras sensibles a las desigualdades de clase y de género hacían sobre el vínculo que las destinatarias tramaban con sus hijos/as, dicho relacionamiento no aparecía caracterizado en términos de «estrategias de sujetas activas». Por el contrario, concentradas sus miradas en el plano subjetivo, no lograban captar que, tal vez, en aquellos contextos desiguales, las mujeres podían gestar modos de poder que, aun conviviendo con la desigualdad, las dotasen de zonas de gestión autónoma.

Estas interpretaciones y expectativas y las prácticas institucionales en las que se encarnaban, tenían como marco el compromiso y la tarea activa del gobierno local en el desarrollo de políticas de igualdad de oportunidades entre varones y mujeres. En este sentido, en el Envión de La Estrella se realizaban numerosas acciones tendientes a cumplir con los lineamientos del plan municipal de igualdad de oportunidades. ${ }^{8}$ Uno de ellos era garantizar que las jóvenes madres, al igual que el resto de los/as destinatarios/as, lograsen participar de todas las instancias previstas por el programa, incluyendo los espacios colectivos.

${ }^{8}$ Por ejemplo, articulaciones con dispositivos del área
de Género; "asambleas" sobre sexualidad y aborto;
actividades con trabajadoras de la salud sobre
métodos anticonceptivos y talleres sobre noviazgos
violentos. Estas intervenciones solían partir de la
presunción de la heterosexualidad de sus
destinatarios/as, estableciendo un determinado
cuerpo legítimo" sobre el cual operar normalizando el
deseo y las configuraciones de las identidades
genéricas y sexuales (Elizalde, 2009; Gaitán, 2019). 
Bajo el entendido de que asistir a estos últimos era central para la emergencia de "proyectos de vida» y de una reflexión colectiva sobre la desigualdad de género, y frente a la interpretación de que el llevar a sus hijos/as las constreñía, pero también, las eximía de "animarse» a "poner el cuerpo», los/as trabajadores/as destinaban múltiples esfuerzos para lograr que las destinatarias participasen del modo demandado institucionalmente. Se ofrecían a cuidarles los/as niños/as durante las "asambleas» y los talleres, buscaban vacantes en jardines maternales públicos de la zona y hasta habían intentado contratar a alguien para que los/as cuidase mientras ellas participaban de los espacios colectivos. Esta última iniciativa, principalmente por la falta de recursos materiales, no logró nunca ser instrumentada.

No obstante estos esfuerzos, muchas de las destinatarias seguían sin participar del modo y en la frecuencia esperada por los/as trabajadores/as. Por lo tanto, durante el año 2011, comenzó a ofertarse un nuevo taller específico para ellas. Este era impartido por el Espacio de Educación Maternal Comunitaria (EEMC), una iniciativa dependiente del área de educación del gobierno local. A pesar de que el EEMC se encontraba dirigido a las mujeres en su calidad de madres y que había sido diseñado para garantizar el «desarrollo normal» de los/ as niños/as del municipio, los/as trabajadores/as del Envión lo ofrecían bajo la expectativa de que, las destinatarias reunidas con otras atravensando experiencias similares, pudieran 
iniciar procesos reflexivos que las habilitaran a desnaturalizar e interrogar políticamente sus experiencias cotidianas como madres jóvenes.

Al igual que otras intervenciones estatales y no estatales tendientes a conseguir la igualdad de género y el desarrollo de las mujeres en países pobres, esta propuesta de espacios de encuentro y trabajo reflexivo entre destinatarias, se construía sobre uno de los elementos centrales del relato feminista acerca de la liberación femenina: la solidaridad entre mujeres (Cornwall, Harrison y Whitehead, 2007). Partiendo de la premisa de que las jóvenes podrían establecer empatía con los relatos y experiencias de sus pares, se esperaba que, al juntarlas a hablar sobre determinados temas, aquellas pudieran tomar conciencia de los intereses y obstáculos que se les presentaban como mujeres en general y como jóvenes madres de sectores populares en particular. Esto les permitiría interrogar sus realidades e iniciar acciones para modificarlas. Si bien la asistencia al EEMC no suplía la expectativa institucional de que aquellas destinatarias participasen de las «asambleas», los/as trabajadores/as del Envión no desestimaban la articulación interprogramática.

Por el contrario, al considerar el Envión como un espacio de contención y protección, como «otra» opción de comunicación y de relacionamiento, diferente a la que se les ofrecía cotidianamente a los/as jóvenes en el barrio, en sus casas y en otras instituciones estatales, que aquellas destinatarias fuesen 
al menos al taller del EEMC, era una garantía de tenerlas «protegidas». Además, a pesar de no desconocer la posibilidad de que parte de la propuesta del EEMC pudiera estimular un «rol maternal» estereotípico, los/as trabajadores/as también consideraban que para algunas, podía ser la posibilidad de aprender a relacionarse con sus hijos/as sin que mediase el uso de la fuerza física, los gritos y la agresión verbal, cuestiones que solían señalarles de manera crítica.

\section{ROMPER CON LAS DEPENDENCIAS PARA QUE EL «SENTIDO COMÚN MATERNAL» EMERJA}

Destinado a mujeres embarazas y madres con hijos/ as de entre 0 y 3 años, lo que distinguía al EEMC de los jardines maternales, era su convocatoria a las mujeres a trabajar en conjunto con la intervención docente "revisando pautas de crianza naturalizadas y heredadas». Como le gustaba decir a su coordinadora, era un programa "pionero»: desde el 2003 se había propuesto llevar la educación maternal fuera de las instituciones de nivel inicial hacia los barrios para, desde una «mirada comunitaria de la educación», desarrollar acciones que permitieran disminuir riesgos en la primera infancia a través de la indagación y modelamiento de las formas de crianza. Coordinado por una trabajadora social, el programa era implementado cotidianamente por un grupo de entre cuatro y cinco trabajadoras. Con excepción de una de ellas que era 
psicóloga y profesora de expresión corporal, todas eran maestras de nivel inicial y maternal y no habían trabajado en ámbitos comunitarios. EI EEMC no era su único trabajo, también se desempeñaban como docentes o preceptoras en instituciones educativas y una como empleada en casas particulares.

Durante el período 2012-2015, el EEMC se impartió en ocho barrios del municipio, incluyendo La Estrella, pero, a diferencia de lo que acontecía en los otros vecindarios, allí sólo se encontraba destinado a «madres adolescentes». ${ }^{9}$ Aunque la iniciativa de lle- $\mid \begin{array}{r}\text { Excepcionalmente participaban otras madres jóvenes } \\ \text { del barrio que no eran destinatarias del Envión. }\end{array}$ var los talleres al barrio había surgido como una estrategia de los/as trabajadores/as del Envión, desde el EEMC también existía un interés por hacerlo debido al «alto número de madres adolescentes» que, supuestamente, allí había. ${ }^{10}$ Al igual que en los otros barrios, cada jornada semanal se encontraba planificada en torno a diferentes actividades «pedagógicas» dedicadas a trabajar el «vínculo madre-hijo» a través

${ }^{10}$ La búsqueda por dar con algún dato cuantitativo que sostuviera esta apreciación resultó infructuosa. Sin encontrarse desagregado por barrio, la cantidad de nacidos/as vivos/as de madres adolescentes de residencia en el municipio entre 2005-2014 mostraba una curva irregular, pero con una tendencia decreciente. En 2012 nacieron vivos/as 393 niños/as de mujeres de entre 10 a 19, mientras que, en el 2014, de la ejercitación de comportamientos y emociones y el aprendizaje de lenguajes corporales nuevos. ${ }^{11}$

${ }^{11}$ Estas actividades podían ser "exploraciones" (trabajo de estímulo de sentidos y de conocimiento del cuerpo de los/as niños/as a través de la experimentación con témperas, comida, música, etc.) o conversaciones y/o consignas de psicodrama para trabajar temas como

Estas intervenciones se diseñaban con base en elaboraciones teóri"lactancia", "límites", "rol del padre", entre otros. cas provenientes de la psicología y centradas en la «importancia» del afecto materno y de las condiciones ambientales favorables 
durante el primer año de vida, para el «desarrollo sano» de los/ as niños/as y evitar daños psicosomáticos «irreparables». Constituyendo esos primeros años un período clave en el cual todo lo que sucediera - malos o buenos hábitos - podía tener una influencia decisiva en el futuro del/la niño/a, de esta manera, las madres tenían la minuciosa y sensible tarea de disminuir sus propios errores.

En el EEMC las destinatarias tenían la oportunidad de entrar en contacto con «información valiosa» respecto de aquello que constituía "lo normal para la edad del niño" y que luego podían trasladar a la dinámica del «hogar». Éstas debían apelar a su «instinto maternal» —el cual las convertía en las mejores candidatas para hacerlo-y dejarse guiar por las trabajadoras para neutralizar todo aquello que pudiera influenciar al niño/a en tan «delicado» momento. Pero como lo explicaban las agentes, cuando se trataba de las destinatarias de La Estrella, la tarea era un poco más compleja que en otros barrios. Si bien de sus relatos se desprendía que la maternidad era algo esencial en ellas y en la mayoría de las mujeres, cuando se referían a las jóvenes madres del Envión solían destacar que se trataba de «un vínculo que cuesta». Como lo mencionaran en más de una oportunidad: no tenían «el sentido común de ser mamás».

Natural, pero ausente, espontaneo, pero inexperto, era en esa contradicción entre una naturaleza maternal femenina instintiva y la necesidad de guiarla, reponerla e incluso cons- 
truirla, que las trabajadoras del EEMC describían la maternidad de dichas jóvenes. Devaluadas sus experticias, puesto en duda su «sentido común maternal», estas madres de La EstreIla se volvían un cuerpo "amenazante» al cual era preciso mostrarle otro modelo de crianza.

Constituida como una acción más entre otras acciones estatales que, atravesadas por la contradicción de construir algo que se supone instintivo y natural de las mujeres, han procurado regular sus vidas (Nari, 2004). El EEMC destinaba esfuerzos a «combatir» relacionamientos que trazaban las destinatarias de La Estrella y que impedían que el «sentido común maternal» emergiese en ellas. Lo que las «desnaturalizaba» eran tres dependencias forjadas: con un tipo de Estado, con las familias y con el barrio. El hecho de que las jóvenes de La Estrella estuvieran «muy» relacionadas al Estado y que, en su condición de madres, administraran dinero de programas $\mathrm{TCl}$, era interpretado por las trabajadoras como algo que generaba efectos nocivos y que su propuesta programática, procuraba cuestionar.

A pesar de que trabajar con los datos otorgados por el Envión era algo que valoraban, constantemente cuestionaban las bases del "acuerdo compromiso» y la ayuda económica provista por dicho programa, alegando que contaminaba su participación «genuina». Para aquellas, el dinero de la beca del Envión parecía ser riesgoso en un doble sentido. La tentación por cobrarlo forzaba a los/as destinatarios/as del Envión a participar de espacios que no deseaban. Y cuando se trataba de las jóve- 
nes madres, mezclaba dos mundos supuestamente irreconciliables: el maternal, asociado a la esfera de la intimidad y el afecto y el del dinero, circunscrito al plano de lo económico (Zelizer, 2009). Interpretadas en términos morales como algo negativo, las transferencias de ingresos eran utilizadas para construir jerarquías entre las destinatarias. Mientras que el desempeño de las pocas jóvenes que asistían sin cobrar beca era destacado y sus equivocaciones «toleradas», el «desaliño» y las llegadas tarde de las destinatarias que sí la cobraban, constituían la piedra angular para tejer un manto de sospecha sobre ellas. Leídas estas acciones como expresión del peso de la «obligación» que el Envión les imponía, iban «para cumplir y que no les quiten la beca» (Registro de campo EEMC, 21/10/2013).

Por otra parte, las trabajadoras solían quejarse de cómo los problemas que había en el barrio se colaban en la dinámica del taller. Para ellas, La Estrella no era como otros vecindarios. Allí todos/as se conocían entre sí y eso implicaba, «inevitablemente», la intromisión de los conflictos barriales en la dinámica del taller restringiendo ciertas participaciones y produciendo rivalidades e inhibiciones entre las jóvenes. Como lo señalaban, ese conocimiento "excesivo» de la vida de los/ as otros/as, inhibía y generaba competencia entre las destinatarias. Para las trabajadoras, el temor al «qué dirán» explicaba, en parte, las formas de participación no deseada, aquella que se caracterizaba por ser "pasiva» frente a las consignas pedagógicas del taller. 
Por último, la tercera batalla que las agentes libraban, era contra sus familias. Muchas de las hermanas y cuñadas de las destinatarias solían acompañarlas al espacio. En reiteradas ocasiones, las participaciones de estas personas eran interpretadas por las trabajadoras como perjudiciales, o al menos incompatibles con el proceso de construcción del "vínculo madre-hijo». De acuerdo a su lectura, había destinatarias que acudían en compañía de estas otras mujeres para delegarles el cumplimiento de las "actividades pedagógicas» y las responsabilidades sobre sus hijos/as, mientras ellas conversaban y "se ponían al día» con las otras madres. Al hacerlo, no entraban en el proceso de aprendizaje vincular propuesto y las posibilidades de que aquello trabajado durante la hora y media de taller, se ejercitase en sus casas, disminuían.

Por lo tanto, si estas presencias en el espacio eran comprendidas como algo que podía entorpecer el forjamiento del "vínculo madre-hijo», también lo eran otros relacionamientos familiares que se producían fuera de la órbita del EEMC, en el cotidiano del «hogar». Las trabajadoras no sólo les sugerían a algunas de las destinatarias que dejasen de asistir con sus hermanas y/o cuñadas, sino que también solían aconsejarles respecto a cómo debían ordenar los «roles» dentro de sus familias. Para ello, seguían modelos de relacionamiento familiar biologicistas y heteronormativos.

Frente a estas - y otras - tensiones y reticencias de las jóvenes a ser pedagogizadas a través de las actividades diagramadas, 
las trabajadoras desplegaban otra estrategia de intervención: la exploración reflexiva del pasado. Para alcanzar la meta de que las madres construyesen o reforzasen un vínculo que se encontraba "debilitado» o incluso "ausente», las agentes promovían que las jóvenes entrasen en un proceso de introspección y de revisión de su pasado y de su crianza. Esta estrategia institucional demandaba que aquellas conectaran con emociones intensas, procurando identificar patrones de comportamiento «nocivos», vivenciados y heredados de sus padres y madres. Al revisar sus recuerdos y exponer sus sentimientos frente a las trabajadoras, otras destinatarias, los/as niños/as y esta investigadora, las jóvenes lograrían poner en evidencia los causales de su «mal» desempeño como madres, ayudándole a construir nuevos modos de vincularse con sus hijos/as.

Esta acción transformadora suponía un revocamiento generacional, es decir, que las jóvenes pudieran llevar a cabo una desidentificación con las prácticas maternales experimentadas como hijas. Factibles de ser examinadas y discutidas, las emociones y experiencias dolorosas del pasado se convertían en materia sujeta a análisis y evaluación y parte constitutiva de un ejercicio de autogobierno de las jóvenes (McKim, 2008). Si las destinatarias lograban entender sus comportamientos como parte de patrones familiares de relacionamientos "dañinos», entonces se alineaban a los intereses de gobierno del programa: producir nuevas subjetividades maternales. 
Para concluir, en la intervención del EEMC la articulación de los discursos de responsabilización y de dependencia operaba como una estrategia individualizadora: cambiaba la definición del problema, de la realidad empírica de la pobreza, a las características individuales de las jóvenes que, en gran parte, se suponían heredadas de las familias (Fraser, 1997). Cegado respecto a los modos en que la pobreza y la marginalidad modelaban la realidad de aquellas destinatarias y sus opciones limitadas, el EEMC las motivaba a romper con tres relacionamientos que podían garantizarles, en lo cotidiano, mejores condiciones de vida a ellas y a sus hijos/as. Las trabajadoras no se cuestionaban si las jóvenes madres de La EstreIla se encontraban preparadas para establecer aquellas independencias, simplemente las estimulaban con la promesa de que forjarlas sería materia de disfrute. Sin atender a los costos que dichas rupturas podían ocasionarles, les prometían que al optar por un modelo de «madre independiente», encontrarían placer en cada momento y actividad vivida con sus hijos/as.

\section{CONSIDERACIONES FINALES}

Colocar la lupa en la implementación local del Envión

de La Estrella permitió evidenciar que allí existía una propuesta de participación específica para las destinatarias madres y/o embarazadas, la cual se sostenía sobre la orquestación programática con el EEMC. Esta orquestación se caracteriza- 
ba por ser dilemática en tanto que, a pesar de tener ambos programas, intereses y objetivos diferentes, y de que la contraparte programática encarnase aspectos de ese Estado del cual cada una pretendía distanciarse, ambos reconocían la utilidad de su articulación. EI EEMC admitía que el Envión le había permitido acceder a una población juvenil con la que hacía tiempo tenía interés en trabajar y en un barrio donde hasta entonces no había logrado ingresar e instalarse.

Por otra parte, el Envión reconocía que, sin el EEMC, la expectativa de que las destinatarias madres participasen de espacios colectivos del programa se encontraba destinada a un «éxito» relativo. Optar por lo que estaba disponible —el EEMCno sólo alejaba aún más a las destinatarias madres de los espacios colectivos comunes del Envión, sino que, al crearse un nuevo circuito específico para ellas, sus intereses y participaciones quedaban restringidas a su desempeño en lo maternal y en las tareas de cuidados, restricción que aquel programa de inclusión social juvenil en La Estrella, buscaba problematizar. Esta orquestación dilemática revela cómo, el Estado y sus políticas sociales, pueden desplegarse de formas complejas, de manera de alcanzar, al menos parcialmente, sus objetivos de regulación (Haney, 2010).

La exploración etnográfica evidenció al menos otras tres cuestiones relevantes. Por un lado, que en el despliegue de una política cuyos objetivos eran de inclusión social, existían micro operaciones tendientes a forjar arreglos de la «intimi- 
dad" y normativos del género y la maternidad. En el circuito participativo se emitían mensajes en competencia respecto al género, a la vez que la categoría «joven» entraba en tensión de diversos modos con los significados normativos acerca de la maternidad y la «autonomía» (Haney, 1996). Estos mensajes eran disímiles y apuntaban a modelar los "modos de» relacionamientos que las destinatarias establecían con sus hijos/ as, familias, parejas heterosexuales, el barrio y las iniciativas estatales.

Esa ambigüedad estatal, donde proliferaban y se imbricaban dos pequeños y diferenciados proyectos de gestión de la «autonomía» evidencia otra segunda y tercera cuestión relevante. Por un lado, que incluso en un espacio tan reducido como un municipio, pueden existir distintos modos de regular estatalmente la maternidad juvenil y el género. Por el otro, que esa ambigüedad producto del carácter precario, inestable y cambiante de las instituciones y dispositivos estatales, tensionaba el discurso político de la gestión municipal respecto a los derechos sociales y la igualdad de oportunidades entre varones y mujeres, volviéndolo más endeble.

Aun cuando ciertos preceptos feministas respecto de la «autonomía femenina» y los cuidados eran incorporados a una matriz estatal de manera articulada con concepciones de derechos, justicia social y equidad, como acontecía en el caso de la implementación del Envión estudiada, a veces la institucionalidad no lograba reflejarlo o, debido al tipo de 
estructura de trabajo municipal, la reflejaba de manera parcial e inestable. La insuficiencia de los recursos que destinaba el municipio, en parte por las limitaciones propias de un Estado local, hacía que la plataforma de políticas públicas construida discursivamente sobre un enfoque de género y anudado a una idea de justicia social, no tuviera una institucionalidad lo suficientemente robusta como para desplegar las intervenciones estatales del modo en que, el equipo del Envión de La Estrella, lo había planeado inicialmente.

\section{Bibliografía}

Anzorena, C. (2013). Mujeres en la trama del Estado. Una lectura feminista de las políticas públicas. Mendoza: EDIUNC

Cornwall, A., Harrison, E. y Whitehead, A. (Eds.). (2007). Gender Myths and Feminist Fables: The Struggle for Interpretive Power in Gender and Development. New Jersey: Blackwell.

ElizALDE, S. (2009). Normalizar, ante todo. Ideologías prácticas sobre la identidad sexual y de género de los/as jóvenes en la dinámica de las instituciones orientadas a la juventud. Revista Argentina de Estudios de Juventud, 1,1-11.

FELITTI, K. (2011). Madre no hay una sola. Experiencias de maternidad en la Argentina. Buenos Aires: Ciccus.

Fraser, N. (1989). Unruly Practices: Power, Discourse, and Gender in Contemporary Social Theory. Minneapolis: University of Minnesota Press. 


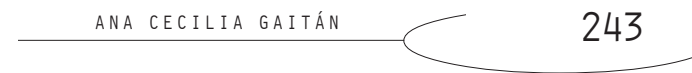

(1997). Iustitia Interrupta. Reflexiones críticas desde la posición "postsocialista». Bogotá: Siglo del Hombre.

GaItÁN, A. (2019). Construir "otra mirada». Tensiones en la participación de jóvenes mujeres en una política social en el Área Metropolitana de Buenos Aires. En G. Gutíerrez Cham y J. Kemner (Eds.) iAquí los jóvenes! Frente a las crisis. Guadalajara: Universidad de Guadalajara. Hammersley, M. y Atkinson, P. (1994). Etnografía. Métodos de investigación. Barcelona: Paidós.

HANEY, L. (1996). Homeboys, babies, men in suits: the state and the reproduction of male dominance. American Sociological Review, 61(5), 759-778. (2000). Feminist State Theory: Applications to Jurisprudence, Criminology, and the Welfare State. Annual Review of Sociology, 26, 641-666.

(2010). Offending Women: Power, Punishment and the Regulation of Desire. Berkeley: University of California Press.

LISTER, R. (2002). Investing in the citizen-workers of the future: New Labour's 'third way' in welfare reform. Fostering social cohesion: a comparison of new policy strategies. Working paper, (5), 1-23.

LLobet, V. (2009). Género y Políticas Sociales para la Infancia y la Adolescencia: ¿Una relación ausente? En S. Ortale, y R. M. Enríquez (Comps.) por, Política Social en América Latina y Género: Configuraciones/ Reconfiguraciones en la participación de las mujeres. Buenos Aires: Biblos.

(Coord.). (2013). Sentidos de la exclusión social. Beneficiarios, necesidades y prácticas en políticas sociales para la inclusión de niños y jóvenes. Buenos Aires: Biblos. 
McKIM, A. (2008). "Getting Gut-Level» Punishment, Gender, and Therapeutic Governance. Gender and Society, 22(3), 303-323.

MEDAN, M. (2013). El gobierno de la "juventud en riesgo» y los programas de prevención social del delito en el AMBA: entre la seguridad y la inclusión (Tesis de Doctorado). Buenos Aires: Universidad de Buenos Aires.

NARI, M. (2004). Políticas de maternidad y maternalismo político. Buenos Aires: Biblos.

Zelizer, V. (2009). La negociación de la intimidad. Buenos Aires: Fondo de Cultura Económica. 